\title{
Electrochemical Monitoring of Cisplatin as Anticancer Compound to the Treatment of Laryngeal Cancer in the Elederly Using Poly(cyanocobalamin) Modified Composite of Ag Nanoparticles Graphene Oxide Electrode
}

\author{
Wei Ni, Qin Li, Yidao Jiang* \\ Otolaryngology Head and Neck Surgery, Jingzhou Central Hospital, Jingzhou, 434020, China \\ *Email: jyd18107167013@163.com
}

Received: 1 October 2021 / Accepted: 29 October 2021 / Published: 6 December 2021

\begin{abstract}
The purpose of this research was to develop a poly(cyanocobalamin) modified composite of Ag nanoparticles graphene oxide (poly(cyc)/Ag-GO) for electrochemical monitoring of cisplatin, a chemotherapy medication used to treat laryngeal cancer. The Ag-GO composite was electrodeposied on a glassy carbon electrode (GCE), and then poly(cyc) was electropolymerized on Ag-GO/GCE. The XRD and FE-SEM structural characterization of Ag-GO nanocomposite revealed that the Ag nanoparticles were discretely distributed on the surface of the GO nanosheets, resulting in a high porous structure with discrete electroactive sites for cyanocobalamin's strong bond and improved electron transfer and signal in electrochemical reactions. Using CV and DPV, electrochemical analyses revealed a stable, sensitive, and selective response of poly(cyc)/Ag-GO/GCE to cisplatin determination. The proposed sensor's detection limit, sensitivity, and linear range were determined to be $0.2 \mu \mathrm{M}, 0.01316 \mu \mathrm{A} / \mu \mathrm{M}$, and 40 $1200 \mu \mathrm{M}$, respectively. The sensor's capability was tested using prepared platinol injection and human serum as real samples, and the results revealed acceptable recovery (95.25\% to $98.50 \%)$ and RSD (3.08\% to $4.76 \%$ ), implying that the proposed cisplatin sensor is accurate enough for clinical sample analysis.
\end{abstract}

Keywords: Cisplatin, Differential pulse voltammetry, Cyanocobalamin; Ag nanoparticles; Graphene oxide; Electropolymerization; Electrodeposition

\section{FULL TEXT}

(C) 2022 The Authors. Published by ESG (www.electrochemsci.org). This article is an open access article distributed under the terms and conditions of the Creative Commons Attribution license (http://creativecommons.org/licenses/by/4.0/). 